\title{
Autorregulación versus regulación. El discurso periodístico sobre la Proposición de Ley de Estatuto del Periodista Profesional (2004-2008)
}

\author{
Eva JiMÉNEZ GÓMEZ \\ Universidad Ramón Llull \\ evajg0@blanquerna.url.edu
}

Recibido: $19 / 11 / 2010$

Aceptado: 11/04/2011

\section{Resumen}

Este artículo constituye una síntesis de una investigación más extensa realizada por la autora y financiada por la Facultad de Comunicación Blanquerna. Dicho trabajo analiza el discurso de algunos periodistas y medios de comunicación sobre la Proposición de Ley de Estatuto del periodista profesional, desde un punto de vista normativo. Para ello, se han empleado dos técnicas principales: análisis de contenido y retórico. La investigación, de carácter cualitativo, presta especial atención a los argumentos utilizados y a los implícitos que subyacen en ellos. Los análisis revelan la profundidad de las diferencias existentes, hasta el punto de que puede hablarse de visiones y actitudes antagónicas sobre la cuestión.

Palabras clave: Periodismo, autorregulación, regulación, estatuto del periodista, análisis de contenido, análisis retórico.

\section{Self-regulation versus regulation. Journalistic Discourse on the Proposition of Law Statute of the Professional Journalist (2004-2008)}

\begin{abstract}
This article is a synthesis of extensive research by the author and funded by Blanquerna Faculty of Communication. This paper analyzes the discourse of some journalists and media on the Proposition of Law Statute of the professional journalist from a normative perspective. To this end, we have used two main techniques: content analysis and a rhetorical one. The research, of a qualitative nature, pays particular attention to the arguments and the implicit ones underlying them. The analysis reveals the depth of differences, to the point where we can talk about opposing views and attitudes on the issue. Key words: journalism, self-regulation, status of journalists, content analysis, rhetorical analysis.

\section{Referencia normalizada}

JIMÉNEZ GÓMEZ, Eva (2011): “Autorregulación versus regulación. El discurso periodístico sobre la Proposición de Ley de Estatuto del periodista profesional (2004-2008)”. Estudios sobre el mensaje periodístico. Vol. 17, núm. 1, págs.: 141-166. Madrid, Servicio de Publicaciones de la Universidad Complutense.

Sumario: 1. Introducción. 2. Qué, por qué y cómo. 2.1. Objeto de estudio. 2.2. Marco teórico. 2.3. Marco metodológico. 3. Contexto político, periodístico, deontológico y jurídico. 3.1. Contexto político. 3.2. Contexto periodístico. 3.3. Contexto deontológico. 3.4. Contextos jurídico. 4. El discurso periodístico. 4.1. Las intervenciones parlamentarias. 4.1.1. Fernando Jáuregui. 4.1.2. Migul Ángel Gozalo. 4.1.3. Víctor Márquez Reviriego. 4.1.4. Miguel Ángel Aguilar. 4.1.5. Dardo Gómez. 4.1.6. Antonio Fontán. 4.2. La opinión de los medios. 4.2.1. El País. 4.2.2 El Mundo. 4.2.3. ABC. 4.2.4. La Vanguardia. 4.3. Otras voces del periodismo. 4.3.1. Juan Varela. 5. Conclusiones. 6. Referencias bibliográficas. 7. Anexos.
\end{abstract}




\section{Introducción}

El presente artículo constituye una síntesis de una investigación más amplia, financiada por la Facultad de Comunicación Blanquerna, en la que se analiza el discurso periodístico sobre la Proposición de Ley de Estatuto del periodista profesional (PLEPP), desde el punto de vista de la autorregulación y/o regulación del periodismo ${ }^{1}$.

La proposición de ley, redactada en el seno del Foro de Organizaciones de Periodistas (FOP)², establecía una definición del periodista profesional, una relación de derechos y deberes de informadores y empresas, y una serie de mecanismos que pretendían facilitar el ejercicio responsable del periodismo: comités de redacción y los llamados consejos de la información ${ }^{3}$.

La admisión a trámite de la PLEPP por parte del Congreso de los Diputados, el 23 de noviembre de 2004, suscitó una viva polémica entre diversos sectores del periodismo, hasta el punto de que la entonces Federación de Asociaciones de la Prensa de España (FAPE) se desvinculó oficialmente del FOP el 12 de marzo de 2005, separación que continúa vigente hasta el día de hoy, a pesar de que la proposición de ley no resultó finalmente aprobada, tras más de cien ampliaciones sucesivas del plazo para presentar enmiendas ${ }^{4}$.

El artículo se ha estructurado del siguiente modo. En primer lugar, se expone el objeto de estudio, el marco teórico y la metodología empleada. Seguidamente, se explica el contexto político, periodístico, deontológico y jurídico existente durante el periodo 2004-2008. En tercer lugar, se sintetizan las ideas fundamentales obtenidas tras el análisis de los discursos. Finalmente, se presentan las principales conclusiones halladas tras la investigación.

\section{Qué, por qué y cómo}

\subsection{Objeto de estudio}

Analizar un discurso no significa únicamente conocer y describir la opinión de los actores seleccionados, sino ahondar también en los implícitos que subyacen en ella, así como en el contexto en que se pronuncia.

${ }^{1}$ La autora agradece a Carlos RuIz CABALLERo la dirección del trabajo.

2 En el momento de su admisión a trámite, el FOP estaba integrado por la Federación de Asociaciones de la Prensa de España, la Federación de Sindicatos de Periodistas, el Colegio de Periodistas de Cataluña y las agrupaciones de periodistas de los sindicatos Comisiones Obreras y Unión General de Trabajadores.

3 Texto en línea: http://www.congreso.es/public_oficiales/L8/CONG/BOCG/B/B_04401.PDF [fecha de consulta: 3 de noviembre de 2010]

${ }^{4}$ En una pregunta parlamentaria formulada en la legislatura actual, el Gobierno se ha comprometido a cumplir “con los compromisos de su programa de investidura”, entre los que figuraba la promulgación de un estatuto del periodista profesional. Las organizaciones periodísticas, sin embargo, siguen divididas: la FAPE cuenta con un texto diferente al del FOP, que ya va por su novena versión; y el FOP habla ahora de un Borrador para el proyecto de Ley Orgánica de Garantías del Derecho a la Información de la Ciudadanía. 
Adoptar un punto de vista normativo implica, a su vez, dos ideas. Por un lado, se trata de un enfoque ideal, en el sentido de que se busca lo mejor en un campo concreto de la sociedad -el periodismo-; y, por otro, se persigue un fin eminentemente práctico, pues se valora una norma con gran capacidad de influencia sobre los profesionales de la información de forma directa y sobre toda la ciudadanía de modo indirecto.

En este trabajo se analizan tres tipos de discursos: comparecencias parlamentarias ${ }^{5}$, editoriales de medios de comunicación y artículos sobre la cuestión. En concreto, se han seleccionado las intervenciones de Fernando JÁUREGUI, Miguel Ángel Gozalo, Víctor Márquez Reviriego, Miguel Ángel Aguilar, Dardo Gómez y Antonio FonTÁN ${ }^{6}$; los editoriales de los principales medios de comunicación impresos: El País, El Mundo, ABC y La Vanguardia; y los artículos publicados en internet por Juan VARELA, periodista y autor de una Wiki sobre el estatuto del periodista profesional? .

La autora de esta investigación es consciente de que la selección no es representativa de toda la profesión periodística española. No es preciso, ya que la finalidad primordial de este trabajo no es de carácter cuantitativo sino cualitativo, es decir, no importa tanto cuántos periodistas se manifestaron a favor o en contra de la proposición de ley como los argumentos que emplearon para defender su postura y los implícitos que subyacían en ellos.

Este trabajo presenta interés, en la medida en que la profesión periodística constituye un actor social de gran relevancia, cuyas decisiones afectan a un considerable número de personas. Analizar con detenimiento su modo de expresarse, sin la interferencia del investigador, constituye un punto de vista privilegiado para detectar cuáles son los principales escollos que atraviesa el periodismo español para hacer frente a sus responsabilidades.

\subsection{Marco teórico}

La adopción de un punto de vista normativo o ideal, por lo tanto, no sólo no nos aleja de la realidad, sino que nos acerca a ella, ya que todo fenómeno comunicativo, por no hablar de toda realidad humana, conlleva las dos dimensiones (WoLton, 1999: 19).

Desde este punto de vista, todavía puede resultar útil tener en cuenta las teorías establecidas por Siebert, Peterson y Schramm en 1963, pues desde este enfoque "será posible medir en cada discurso público a propósito del periodismo, cuál es el

5 En realidad, no se trata propiamente de comparecencias parlamentarias, sino de exposiciones realizadas a puerta cerrada que sirven como material de trabajo para los grupos parlamentarios. La autora agradece al equipo del archivo del Congreso de los Diputados, especialmente a Sofía Gandarias, el acceso a las intervenciones.

${ }^{6}$ El trabajo analiza únicamente las exposiciones de las que se conserva transcripción íntegra, bien facilitada por el Congreso, bien transcrita por la autora a partir de un documento sonoro.

7 Texto en línea: http://www.escolar.net/wiki/index.php/Estatuto_del_periodista_profesional [fecha de consulta: 3 de noviembre de 2010] 
principal tipo ideal de referencia y aquéllos que son rechazados totalmente o en parte” (DEMERS, 1998: web).

La hipótesis de partida, por tanto, reside en la idea de que los discursos analizados en este trabajo se aproximarán o alejarán de alguna de estas tres teorías de la prensa: libertaria, que establece que los medios deben estar libres del control del estado; de la responsabilidad social, que considera que el gobierno puede intervenir para proteger la libertad de los ciudadanos; y de la participación democrática, que se interesa principalmente por acercar los media a los usuarios (McQuaIL, 2000: 211).

Detrás de cada una de estas teorías subyacerá, además, una visión y actitud sobre "la naturaleza del hombre, la naturaleza de la sociedad y el estado, la relación del hombre con el estado, y la naturaleza del conocimiento y la verdad”, entre otras (SIEBERT et al., 1963: 2).

Otras hipótesis se refieren a las causas o factores que influyen en la adopción de uno u otro punto de vista. Así, presuponemos que un periodista que ocupe o haya ocupado un puesto directivo durante largo tiempo tiene más posibilidades de rechazar la regulación jurídica, pues se identifica más con la empresa, que otro que no ha desempeñado funciones directivas o que ejerce su oficio en condiciones de precariedad y se siente desamparado.

La sensibilidad ética, la ideología política y los condicionamientos empresariales y tecnológicos también podrían tener relevancia dentro de los discursos periodísticos. Así, tendemos a pensar que los medios afines a la ideología liberal, como El Mundo o $A B C$, se opondrán a la regulación con más fuerza que otros más próximos al socialismo, como el diario El País.

\subsection{Marco metodológico}

La metodología empleada intenta complementar los métodos cuantitativos y cualitativos. Los primeros nos ayudan a mantener una cierta distancia, una cierta objetividad en el mejor sentido de la palabra, pero pueden trocear tanto la realidad que podríamos ser incapaces de encontrarle una explicación o sentido. Los cualitativos, por su parte, permiten alcanzar una visión mucho más completa y profunda, si bien tienen el peligro de conducir a un exceso de interpretación o subjetivismo, en la peor acepción del término.

Es por ello que en esta investigación se ha optado por combinar el análisis de contenido, más próximo a las metodologías cuantitativas (SÁNCHEz ARANDA, en BERGANZA CONDE y RuIZ SAN RomÁn, 2005: 207-228), con el retórico, más próximo a las cualitativas, si bien esta distinción no es rígida ni estanca, aunque sólo sea porque el investigador que analiza es un sujeto único e indivisible.

${ }^{8}$ Se ha obviado la explicación de la teoría autoritaria y una de sus variantes, la comunista soviética, por entender que carecen de vigencia en el territorio español. Es decir, el trabajo presupone que los medios cumplen un papel relevante en el desarrollo y mantenimiento del sistema democrático, tal y como sostienen autores como Kovach y Rosenstiel o Carlos Ruiz. 
En relación con el análisis de contenido, se han seguido fundamentalmente las orientaciones de Laurence BARDiN en su libro del mismo título. A partir de su explicación del análisis categorial, de la evaluación, de la enunciación, de la expresión, de las relaciones y del discurso, se ha elaborado una tabla por cada discurso analizado donde figuran los siguientes elementos: tema principal o categoría, orden de aparición, tamaño (número de palabras), frecuencia (número de veces que aparece), dirección (positiva, negativa, neutra o ambivalente), intensidad (fuerte, débil o media) y contingencia (categorías secundarias que se mencionan al hilo de la principal).

Para el análisis retórico, se han dividido los discursos en las partes clásicas (exordio o introducción, narratio o parte central y peroratio o conclusión) y, dentro de cada una de ellas, se han dividido los textos en función del tipo de argumentos empleados, tal y como distingue José Antonio Caballero López: “lógicos” y, dentro de ellos, premisas deductivas o ejemplos inductivos ${ }^{9}$; psicológicos (apelan a las emociones); éticos (contribuyen a reforzar la autoridad del emisor); y estilísticos (a mayor cuidado, más posibilidades de usar figuras retóricas).

Finalmente, se presta una atención especial al contexto en que se tramita la Proposición de Ley de Estatuto del periodista profesional, hasta el punto de dedicarle un apartado específico, pues entendemos, con Teun A. VAN DIJK (2000: 32), que "el contexto parece implicar algún tipo de entorno o circunstancias para un suceso, acción o discurso. Algo que necesitamos saber para comprender en forma apropiada el suceso, la acción o el discurso".

Entre las múltiples formas de hacerlo, se ha optado por ir de lo más general a lo más específico. Se comienza así por el contexto político del país, se sigue por lo que afecta a la profesión periodística en general y se termina con el contexto normativo (deontológico y jurídico) que afecta a los profesionales de la información periodística en particular.

\section{Contexto político, periodístico, deontológico y jurídico 3.1. Contexto político}

La octava legislatura comenzó marcada por un hecho trágico: los atentados del 11 de marzo de 2004, que provocaron casi dos centenares de muertos y cerca de dos mil heridos. A partir de ese momento, el Partido Popular (PP), hasta entonces en el poder, y el Partido Socialista Obrero Español (PSOE), aspirante al gobierno de la nación, entrarían en un cruce de acusaciones que se amplificaría y, en algún caso, se distorsionaría a través de los medios de comunicación.

No en vano, las víctimas del atentado criticarían muy duramente tanto a los partidos como a los medios durante su intervención ante la comisión de investigación creada al efecto (MANJóN, 2004: web). Los propios periodistas tampoco se librarían de la presión y reconocerían sentirse utilizados por un poder

\footnotetext{
${ }^{9}$ Se ha escrito "lógicos” entre comillas, porque la retórica, a diferencia de la lógica, no argumenta siempre con silogismos ciertos y verdaderos, sino con lo que Aristóteles denominó entimemas y con ejemplos.
} 
político-mediático más o menos fácil de identificar (RovIRA, 2007: número especial; ZARZALEJOS, 2008: 23). Algunos han llegado incluso a hablar de la existencia de una teoría de la conspiración orquestada por medios de comunicación de tendencia liberal-conservadora y miembros del PP, con el fin de crear un clima de crispación que duraría toda la legislatura (EsTEFANíA, 2008: 14-17, 44-47).

En el ámbito de la comunicación, la polémica político-mediática llegaría de la mano de iniciativas como la Ley 10/2005, de 14 de junio, por la cual aparecerían dos canales más para emitir en analógico (Cuatro y La Sexta); o la Ley 17/2006, de 5 de junio, por la que se reformaban los medios de titularidad estatal, a partir de un informe elaborado por un supuesto grupo de expertos denominado 'comité de sabios'.

La promulgación de un estatuto del periodista, por el contrario, no llegaría a cuajar, a pesar de ser una de las promesas electorales del propio presidente del Gobierno, José Luis RodRíGUEZ ZAPATERO (2003: web). De hecho, llama bastante la atención que, durante la legislatura anterior, el PSOE votara a favor de una propuesta prácticamente idéntica sin poner ningún reparo y, una vez en el poder, votara a favor de su admisión a trámite, pero con matices y objeciones muy importantes, hasta el punto de plantear la posibilidad de elaborar un texto alternativo que pudiera servir de "enmienda de totalidad"

Algunos consideran que Rodríguez Zapatero tuvo miedo a los propietarios de los medios de comunicación, quienes no veían con buenos ojos la aprobación de una ley que otorgara más independencia a los periodistas (Gómez; Herrera, 2010: conferencia). Sea como fuere, el hecho es que el PSOE no cumplió su promesa y el derecho a la información de los ciudadanos siguió -y sigue- sin estar suficientemente garantizado.

\subsection{Contexto periodístico}

Los profesionales de la información periodística, sin embargo, no parecían excesivamente turbados ante este hecho. Lo que más les inquietaba en ese momento era su situación laboral. La Encuesta sobre autoestima e identidad profesionales, promovida por la Asociación de la Prensa de Madrid, revela que, entre 2004 y 2008, los problemas que más preocupaban a los periodistas españoles eran, por este orden, el intrusismo (20,5\%), la baja remuneración (13,7\%), el paro y la inestabilidad (13,6\%), y los estudiantes o becarios que ejercían tareas profesionales (6,2\%). A las cuestiones laborales les seguían la falta de códigos éticos (4,8\%), y la inseguridad y/o peligrosidad $(4,5 \%)^{11}$.

${ }^{10}$ Para la legislatura anterior, puede consultarse el Diario de Sesiones del Congreso de los Diputados. Pleno y Diputación Permanente. VII legislatura. Núm. 302. 9 diciembre 2003, pp. 15.979-15.988. Para la que se analiza en este trabajo, Diario de Sesiones del Congreso de los Diputados. Pleno y Diputación Permanente. VIII legislatura. Núm. 50. 23 noviembre 2004, p. 2.368.

${ }^{11}$ Los datos se han obtenido a partir de la media de los porcentajes que figuran en los informes de la Asociación de la Prensa de Madrid entre 2004 y 2008. 
Curiosamente, los periodistas también tenían muy claro dónde residía el principal obstáculo para mejorar su situación laboral. Cuando en el Informe Anual de la Profesión Periodística 2008 se les pregunta por las causas de la precariedad, un inmensa mayoría (92,4\%) considera que ésta es fruto de una "estrategia de las empresas para reducir costes”.

Y si es cierto que la situación laboral condiciona, y mucho, la autonomía profesional (LóPEz HidALGO, 2006: web), no puede extrañarnos que los periodistas españoles valoraran en 4,68 puntos, de un total de diez, su grado de independencia entre 2004 y 2008 (Asociación de la Prensa de Madrid, 2004-2008).

Y, una vez más, las principales presiones de los periodistas procedían de su propia empresa y/o institución $y$, como podría suponerse, a través de su jefe inmediato. Las instancias ideológicas, no obstante, no se quedaban a la zaga, seguidas de las influencias de tipo económico, como anunciantes y otras empresas externas, tal y como se puede apreciar en la tabla número uno.

Queda claro, por tanto, que los periodistas españoles eran muy conscientes de su situación laboral y profesional, y de quién era el principal responsable de dicho estado: la propia empresa para la que trabajaban. Más todavía. Cuando se les pregunta, entre 2004 y 2007, "si el mercado regula por sí solo las funciones de los medios respetando los principios de la cultura democrática”, un 73,25\% responde negativamente (Asociación de la Prensa de Madrid, 2007: 68). Y si se les interroga, en 2004 y 2005, acerca de "cuál debe ser el papel del Estado en relación con la información", un $71 \%$ afirma que "son necesarias políticas informativas que garanticen la libertad de expresión y el derecho a la información” (Asociación de la Prensa de Madrid, 2005: 37).

Entre 2006 y 2007, sin embargo, un 62,15\% se muestra partidario de la autorregulación, rechazando "la regulación de la actividad periodística por parte de alguna institución u organismo externo” (Asociación de la Prensa de Madrid, 2007: $68)$.

¿A qué se debe tal cambio de actitud? ¿Había pasado el peor momento de la crispación político-mediática y ya no se percibía la necesidad de proteger al periodista ni el derecho a la información de los ciudadanos por la vía legal? ¿Tal vez se trataba de una formulación demasiado imprecisa y cuya adjetivación (algo "externo") podría herir la sensibilidad del periodista, al que le gusta verse como profesional liberal?

El hecho de que un 70,9\% de los informadores considere la precariedad laboral como "un fenómeno estructural, [que] no depende de los ciclos económicos", denota un cierto determinismo y, por tanto, una cierta resignación que habría de tenerse en cuenta (Asociación de la Prensa de Madrid, 2008: 67). Conformismo, desconfianza o apatía que los propios profesionales asumen cuando reconocen en más de un $80 \%$ que su "nivel de sindicación y organización” no es el adecuado (Asociación de la Prensa de Madrid, 2005: 34). 


\begin{tabular}{|c|c|c|c|c|c|}
\hline \multicolumn{6}{|c|}{ TABLA 1. Procedencia de las presiones. Respuesta múltiple } \\
\hline & $\begin{array}{c}2008 \\
\%\end{array}$ & $\begin{array}{c}2007 \\
\%\end{array}$ & $\begin{array}{c}2006 \\
\%\end{array}$ & $\begin{array}{c}2005 \\
\%\end{array}$ & $\begin{array}{c}2004 \\
\%\end{array}$ \\
\hline De su empresa o institución (1) & 25,5 & 21,6 & 21,5 & 26,2 & 34,9 \\
\hline De instancias políticas (2) & 20,4 & 23,0 & 18,2 & 22,2 & 20,9 \\
\hline De su jefe inmediato (1) & 24,6 & 17,5 & 24,0 & 20,7 & 31,5 \\
\hline De os anunciantes (3) & 09,9 & 08,4 & 08,6 & 09,0 & 26,2 \\
\hline De instancias empresariales externas (3) & 09,6 & 08,6 & 06,1 & 08,2 & 16,7 \\
\hline $\begin{array}{l}\text { De representantes de las instituciones } \\
\text { públicas (2) }\end{array}$ & 05,4 & 04,4 & 04,2 & 04,5 & 07,4 \\
\hline De otros grupos de presión (2) & 01,8 & 03,1 & 02,6 & 02,7 & 05,3 \\
\hline De otros & 00,7 & 01,3 & 00,8 & 00,0 & 00,8 \\
\hline No ha recibido presiones & 42,8 & 44,2 & 43,2 & 37,9 & 25,4 \\
\hline Total 1 & 50,1 & 39,6 & 45,5 & 46,9 & 66,4 \\
\hline Total 2 & 28,0 & 30,5 & 22,4 & 29,4 & 33,6 \\
\hline Total 3 & 19,5 & 17,0 & 14,7 & 17,2 & 42,9 \\
\hline
\end{tabular}

\subsection{Contexto deontológico}

Los periodistas españoles son conscientes de su precariedad laboral y, algo menos, de cómo ésta puede estar influyendo en su autonomía profesional y en el derecho a la información de los ciudadanos. Tal vez por ello prefieran seguir apostando por la autorregulación, confiados en el poder de su ética personal, la de sus compañeros y la de los propietarios de los medios en los que trabajan. Ahora bien, ¿con qué mecanismos de autorregulación contaban los periodistas entre 2004 y 2008? Y, tal vez, más importante, ¿hasta qué punto eran eficaces para solventar los problemas mencionados?

Desde un punto de vista cuantitativo, no puede negarse que en ese momento ya existían un gran número y variedad de mecanismos de autorregulación: códigos deontológicos, libros de estilo, defensores del lector/espectador/oyente, estatutos de redacción y, en menor medida, consejos de la información y consejos audiovisuales (ver anexo I). Ahora bien, desde un punto de vista cualitativo, resulta mucho más complicado determinar su grado de eficacia.

Si se toma, por ejemplo, el caso de los códigos deontológicos aprobados mayoritariamente por la profesión, el del Colegio de Periodistas de Cataluña (1992) y el de la Federación de Asociaciones de la Prensa de España (1993), se observa que los dos documentos cuentan con espacios donde figuran todos o algunos de los principales problemas que afectan al gremio.

El código del Col-legi menciona en su introducción que la importante función social del periodista "exige salvaguardar permanentemente" los principios expuestos de "cualquier intento de restricción o coacción procedente de toda forma de poder, así como de su posible degradación, producida por su eventual inobservancia o adulteración por parte de los propios medios o de quienes trabajan en ellos". Es decir, los periodistas no sólo pueden, sino que deben ir en contra de quienes vulneran su autonomía profesional, sean quienes sean. 
El código de la FAPE, por su parte, establece el deber del periodista de reclamar, "para sí y para quienes trabajen a sus órdenes”, el derecho a "unas dignas condiciones de trabajo" (II.8.a), así como "el deber y el derecho de participación en la empresa periodística, para que se garantice su libertad informativa de manera compatible con los derechos del medio informativo en el que se exprese" (II.8.c). Más todavía, el informador profesional tiene el "el deber y el derecho de oposición a cualquier intento evidente de monopolio u oligopolio informativo, que pueda impedir el pluralismo social y político” (II.8.b).

Como puede observarse, la federación española reconoce más problemáticas profesionales que el colegio catalán, si bien ésta no deja claro qué sucede cuando el medio va en contra de la deontología periodística, esto es, en contra de los profesionales cuya prioridad es hacer efectivo el derecho a la información de la ciudadanía.

El reconocimiento público de los deberes profesionales, aun siendo necesario, no resulta suficiente, y las dos organizaciones periodísticas son conscientes de ello cuando remiten a "la correspondiente reglamentación", en el caso de la FAPE, o a "un organismo arbitral, representativo, plural e independiente de los poderes públicos”, en el caso del Col-legi. Pero no todo es tan fácil. El Consejo de la Información de Cataluña tendría que esperar a 1997 para constituirse. La FAPE tardaría bastante más, y no conseguiría poner en marcha un Consejo Deontológico hasta mayo de 2004, actual Comisión de Quejas y Deontología.

La eficacia de dichos mecanismos es una cuestión discutida. Algunos autores, como Hugo AzNAR, consideran que la deontología es útil, en la medida en que se consiga un trabajo complementario -que no coordinado- entre todos los instrumentos de autorregulación (AzNAR, 2005: 68). Otros, por el contrario, reconocen sin ambages que estos mecanismos suscitan una "insalvable hostilidad" por parte de los medios, con lo que no son "excesivamente optimistas" acerca de su eficacia (RAMOs, 2003: 243, 253).

La cuestión queda abierta mientras no se realicen investigaciones que demuestren la validez de unos u otros asertos. No obstante, sí podría tenerse en cuenta que la firma de sendos convenios de autorregulación por parte de los responsables de las cadenas de televisión en 1993 y 2004 no contribuyó, o no excesivamente, a mejorar la calidad de los contenidos audiovisuales, tal y como pusieron de relieve algunas asociaciones de telespectadores ${ }^{12}$.

\subsection{Contexto jurídico}

Por lo que respecta al marco jurídico español, la Constitución de 1978 constituye una referencia ineludible. Como es sabido, en su artículo 20 se mencionan los derechos de todos los ciudadanos españoles -periodistas profesionales o no- a la libertad de expresión (art. 20.1 a) y a la información veraz (art. 20.1.d). Estos derechos tienen un doble carácter, en la medida en que son individuales, "invocables

12 Como botón de muestra, véase: http://www.ucm.es/info/vivataca/ficheros/n77/INFOR MEATR-VILLANUEVAjunio2006.pdf [fecha de consulta: 3 de noviembre de 2010] 
ante los poderes públicos y los demás ciudadanos”; y colectivos, dado que "informan el orden social y la democracia” (CARRERAS, 2008: 28).

La libertad de expresión de los ciudadanos no es objeto de estudio de este trabajo, pues nadie cuestiona su derecho individual a expresarse como mejor les parezca. La cuestión nos interesa en su vertiente objetiva, esto es, en la medida en que la libertad de expresión de medios y periodistas influye en la calidad de la democracia que poseemos todos. Del mismo modo, este trabajo tampoco se centra en el derecho de los ciudadanos a comunicar información veraz, sino en su derecho a recibirla por parte de medios e informadores profesionales. Si prestamos una especial atención al derecho a la libertad de expresión y de información de los periodistas es porque estos constituyen el eslabón más débil dentro del sector de la Comunicación, tal y como se ha intentado mostrar anteriormente.

Pues bien, la única ley que existía entre 2004 y 2008 para proteger al periodista de posibles injerencias externas era la Ley Orgánica 2/1997, de 19 de junio, reguladora de la cláusula de conciencia de los profesionales de la información ${ }^{13}$. En el preámbulo se deja claro que el trabajo de los profesionales de la información:

“está presidido por un indudable componente intelectual, que ni los poderes públicos ni las empresas de comunicación pueden olvidar. La información no puede ser objeto de consideraciones mercantilistas, ni el profesional de la información puede ser concebido como una especie de mercenario abierto a todo tipo de informaciones y noticias que son difundidas al margen del mandato constitucional de veracidad y pluralismo”.

El artículo tres resulta especialmente importante para defender el derecho a la libertad de expresión de los informadores, pues les permite negarse a elaborar informaciones contrarias a la ética de la comunicación, sin que ello les acarree sanción o perjuicio. De hecho, el artículo dos sostiene que los periodistas tienen derecho a una indemnización no inferior a la pactada en su contrato o, en su defecto, a la establecida en caso de despido improcedente.

Sin embargo, este articulado no garantiza que los ciudadanos reciban información veraz y plural, como exige la Constitución y recuerda el artículo uno. Si un periodista se niega a elaborar o presentar una información que no es veraz ni plural, dicha información puede que no llegue a intoxicar a los ciudadanos, pero eso no significa que estos lleguen a conocer lo que realmente sucede y mucho menos lo que ha ocurrido dentro del medio de comunicación.

La pésimas condiciones laborales en las que trabaja la mayoría de los periodistas tampoco ayudan, ya que un informador profesional sabe que invocar la cláusula ante

${ }^{13}$ En breve, los profesionales que trabajan en medios audiovisuales podrán apelar a la Ley 7/2010, de 31 de marzo, General de la Comunicación Audiovisual, donde está prevista la creación de un Consejo Estatal de Medios Audiovisuales que vele por los derechos y obligaciones establecidos en la ley (art. 45). Entre ellos, se encuentra "el derecho a que la comunicación informativa se elabore de acuerdo con el deber de diligencia en la comprobación de la veracidad de la información y a que sea respetuosa con el pluralismo político, social y cultural” (art. 4.5.). Lamentablemente, no se avanza demasiado respecto a lo que contemplado en la Constitución Española. 
su medio puede dejarle marcado de por vida. Por ello, ante la disyuntiva entre trabajo y derecho a la información de la ciudadanía, la mayoría opta por lo primero y no se arriesga a llevar adelante un proceso judicial, costoso en tiempo, dinero y prestigio profesional (NAVARRO MARCHANTE y RoDríGUEZ BorgES, 2004: web).

El derecho vigente, por tanto, tampoco parece resultar efectivo, ya que la única ley que vela expresamente por la autonomía profesional no protege adecuadamente a los periodistas y, por tanto, tampoco a los ciudadanos, con lo que la prensa incumple su misión de mantenimiento y consolidación de la democracia.

\section{El discurso periodístico}

Una vez conocido el contexto en el que se pronuncian los discursos seleccionados, llega el momento de exponer los resultados obtenidos a partir de los análisis de contenido y retórico. El limitado espacio de un artículo nos impide profundizar adecuadamente, por lo que nos limitamos a ofrecer los rasgos principales de cada discurso, con la esperanza de que los interesados acudan al trabajo original.

\subsection{Las intervenciones parlamentarias}

\subsubsection{Fernando Jáuregui}

El 1 de diciembre de 2005, el entonces director del diario digital Ocio Crítico, Fernando JÁUREGUI (Santander, 1950), se muestra contrario a la aprobación de la Proposición de Ley de Estatuto del periodista profesional, si bien valora muy positivamente la apertura de un debate sobre la cuestión.

El periodista digital se basa en dos argumentos principales: peligrosidad y sinsentido. Sus grandes preocupaciones residen en que el poder político controle la información, como ya ocurrió durante el franquismo (argumento psicológico), y que no se tengan en cuenta los cambios, tecnológicos principalmente, que se están produciendo en el sector de la información (premisa "lógica").

Jáuregui, sin embargo, reconoce que el derecho de los ciudadanos se halla "lesionado" y que es preciso actuar de algún modo. A su entender, la autorregulación sería la opción más adecuada, liderada por asociaciones de la prensa o colegios de periodistas. Así, propone la creación de buzones de denuncia, donde los ciudadanos puedan expresar sus quejas; y la constitución de un organismo donde tengan cabida periodistas, editores, juristas, políticos e incluso usuarios de la comunicación. No obstante, el profesional intuye que la falta de autocrítica de los informadores dificultará, y mucho, la eficacia de la autorregulación.

El director de Ocio Crítico, por tanto, podría encuadrarse dentro de la teoría libertaria de Siebert, Peterson y Schramm, por lo que tiene de rechazo de la regulación, pero con algunos matices de la de responsabilidad social y la de participación democrática, pues insiste en la necesidad de limitar los abusos de la libertad periodístico-mediática y de tener en cuenta los nuevos medios de participación ciudadana, que están modificando el concepto de periodista. 


\subsubsection{Miguel Ángel Gozalo}

El ex director de Televisión Española (1982-1989) y la Agencia Efe (1996-2004), Miguel Ángel GozALo (Madrid, 1938), también rechaza la PLEPP, el 24 de abril de 2006. Sus argumentos principales residen en la defensa de la libertad de expresión y la libertad de empresa.

El discurso comienza con una digresión sobre la censura franquista, lo cual podría interpretarse como una advertencia de tipo psicológico aplicable al plano personal y social: cuidado, que a mí me marcó el régimen y puede que lo diga que esté condicionado por ello; cuidado, no vayamos a perder ahora la libertad que tanto nos ha costado conseguir.

La libertad de empresa queda claramente defendida cuando sostiene que "la libertad de prensa es la libertad de los dueños de los medios". Desde este punto de vista, no extraña que el exdirectivo no encuentre sentido a la obligación de crear comités de redacción y consejos de la información, como figura en la proposición de ley. Los derechos del público a una información veraz y relevante se limitan, por tanto, a saber "de qué pie se cojea” en cada medio de comunicación, y nada más.

Las soluciones que ofrece tampoco son muy halagüeñas. No le convence la deontología profesional, pues ésta carece de capacidad para obligar a sus miembros. El exdirector de TVE y la Agencia Efe apuesta de modo explícito por el Código Penal y la legislación ordinaria, pero en otro momento de su discurso reconoce que él tuvo pereza a la hora de recurrir a los tribunales cuando debió hacerlo, con lo que su argumentación pierde credibilidad.

Gozalo encaja perfectamente con la teoría libertaria de la prensa, pues el derecho a la libertad de los dueños de los medios pesa mucho más que la de los periodistas y, por supuesto, que la de los ciudadanos.

\subsubsection{Víctor Márquez Reviriego}

El tercer ponente intervino en calidad de periodista el 24 de abril de 2006, si bien en el momento de su comparecencia trabajaba como responsable de prensa del Defensor del Pueblo.

El discurso de Márquez Reviriego (1936, Castillejos, Huelva) resulta difícil de interpretar, pues se halla plagado de ambivalencias. No obstante, queda claro que el profesional no es partidario de crear leyes específicas para periodistas, sino que recomienda a los parlamentarios que se limiten a aplicarles "la ley que se aplica a cualquiera”.

Los motivos en los que se basa para justificar su posición se basan, básicamente, en dos: el miedo a que se cree un poder paralelo al judicial que abuse de su autoridad; y el exceso de idealismo que, a su juicio, impide aplicar algunos de los contenidos de la proposición. Las reminiscencias franquistas (elemento psicológico) vuelven a hacer acto de presencia, así como un cierto escepticismo ante la posibilidad de medir valores éticos (la veracidad o el interés público, por ejemplo).

La alternativa de la autorregulación tampoco le convence demasiado, a juzgar por el escaso espacio que le dedica al tema. Más bien, pone el acento en la ética 
personal de cada profesional, aun a sabiendas, por propia experiencia personal, que los informadores independientes tienen todas las de perder.

En definitiva, puede afirmarse que el cronista parlamentario también encaja perfectamente en la teoría libertaria, pues no cabe ningún tipo de restricción a la libertad de los periodistas. Los conflictos entre medios y periodistas parecen saldarse con la derrota de estos últimos, sobre todo en el plano laboral, aspecto en el que Reviriego se detiene largamente, hasta el punto de pedir, esta vez sí, una intervención política clara.

\subsubsection{Miguel Ángel Aguilar}

El entonces secretario general de la Asociación de Periodistas Europeos, Miguel Ángel Aguilar (Madrid, 1943), tampoco es partidario de la PLEPP, aunque estaría dispuesto a aceptar una regulación específica que legislara sobre asuntos de "extrema necesidad".

El 22 de mayo de 2006, los aspectos que menos le convencen son la concesión de acreditaciones por parte del Consejo Estatal de la Información, tanto por las resonancias franquistas que evoca (elemento psicológico emotivo) como porque cree que puede buscarse una forma "menos dañosa o más equilibrada". La obligatoriedad de crear comités de redacción le parece exigible en los medios públicos, no así en los privados, donde sería más apropiada la autorregulación.

No obstante, no es partidario de incluir un código deontológico dentro de una ley ni mezclar lo laboral con lo profesional, por más que la precariedad le parezca un asunto grave. La autorregulación podría fomentarse mejor a través de lo que denomina comisiones de prensa, encargadas de mediar en caso de conflicto, dado que los tribunales son lentos y los magistrados temen enfrentarse a los periodistas.

Aguilar, por tanto, se hallaría a caballo entre la teoría libertaria y la de la responsabilidad, pues admite que los medios cometen excesos que deben ser corregidos. Ahora bien, ¿cómo podrá el periodista hacerles frente si no existe un comité de redacción que le proteja? La pregunta queda sin respuesta.

\subsubsection{Dardo Gómez}

Como presidente del Sindicato de Periodistas de Cataluña (SPC), una de las organizaciones promotoras de la Proposición de Ley de Estatuto del periodista profesional, no resulta extraño que Dardo Gómez (Buenos Aires, 1937) defienda el texto, tal y como está planteado. El argumento es muy "lógico": la ley presentada no constituye un ataque a la libertad de medios ni periodistas, sino una garantía para su uso adecuado, de tal forma que "el lector o el oyente no se vea confundido en su buena fe, creyendo estar escuchando información cuando se le está dando opinión”.

La defensa de la regulación no constituye un rechazo frontal a la autorregulación sino, más bien, una respuesta a la constatación de que ésta es ineficaz si no tiene capacidad de sanción. De ahí la apuesta del presidente del SPC por defender un organismo regulador "independiente".

El director de la revista Repropres y de boletín ReproOnline también es 
consciente de que las condiciones laborales influyen en la autonomía profesional, motivo por el cual insta a los parlamentarios a aprobar la disposición transitoria segunda, que pretende atajar la precariedad.

Los comités de redacción también le parecen fundamentales, en la medida en que permiten a los "obreros" opinar sobre la calidad de su trabajo, un derecho del que los periodistas carecen.

Finalmente, el sindicalista parece querer contrarrestar el miedo que atenaza a gran parte de los periodistas con otro temor: "Me da mucho miedo [...] que terminemos creyéndonos hasta los políticos que no somos capaces de gestionar un organismo independiente, como si tuviéramos algún pecado de génesis [...]. Es decir, como si hubiera madurez distinta en el resto del mundo con respecto a lo que se puede generar en España”.

El discurso de Dardo Gómez se inserta, por tanto, dentro de la teoría normativa de la responsabilidad social. Es cierto que concede una gran importancia al derecho de la ciudadanía a una información veraz, pero ésta es concebida de forma pasiva, por lo que no nos parece adecuado ubicarle dentro de la teoría democrático-participativa.

\subsubsection{Antonio Fontán}

El 20 de noviembre de 2006, el entonces presidente del Consejo Deontológico de la Federación de Asociaciones de la Prensa de España, Antonio FonTán (Sevilla, 1923 - Madrid, 2010), no comparte la formulación que aparece en la PLEPP, si bien tampoco se cierra totalmente a la promulgación de una norma jurídica alternativa, tal y como defiende la asociación que representa.

Los argumentos para rechazar la propuesta del Foro de Organizaciones de Periodistas descansan en tres pilares: por ser intervencionista, por ser superflua y por ser contraria al espíritu de libertad presente en el artículo 20 de la Constitución. Otras críticas, que podrían calificarse como menores, se refieren a su carácter redundante, inasumible, falta de realismo e incapacidad para adaptarse al contexto actual.

El Consejo Estatal de la Información se lleva las críticas más feroces, pues el editor de Nueva Revista de Política, Cultura y Arte considera que se trata de un organismo "abiertamente intervencionista, [...] politizado por la misma selección de los miembros [...] e incluso politizante por la relación que se puede establecer entre los miembros de ese consejo y su significación política”.

Este temor al control de la información por parte de la clase política parece fundamentarse en malas experiencias pasadas, tanto personales como colectivas, mezclándose, una vez más, los argumentos de tipo "lógico" con los de carácter psicológico.

Los comités de redacción tampoco le convencen, pues considera que la participación de los periodistas en la orientación editorial del medio "depende de la empresa o de la dirección". Por el contrario, es partidario de fortalecer los mecanismos de autorregulación existentes, si bien reconoce que la Comisión de Quejas y Deontología de la FAPE no tiene una demanda social "muy grande”.

Su postura puede ubicarse, por tanto, dentro de la teoría libertaria, ya que la 
defensa de la libertad de los profesionales -periodistas y, sobre todo, empresariosestá por encima de la protección de los derechos de los ciudadanos. De hecho, le cuesta muchísimo reconocer que existe la precariedad y los problemas profesionales que esta conlleva.

\subsection{La opinión de los medios}

\subsubsection{El País}

El diario El País (1976) publica un único editorial el 25 de octubre de 2005. En él, critica la PLEPP con intensidad fuerte: a) "constituye la peor solución posible que cabía imaginar"; b) "si la situación es preocupante, peor es el remedio”; c) "se trata de un despropósito sin paliativos".

El núcleo de la argumentación gira en torno a "la intromisión de los poderes públicos” pues, según los editorialistas, "el proyecto español opta por un intervencionismo de hechuras rancias, cuyo regusto autoritario no puede más que preocupar a cualquiera que considere que el periodismo en libertad constituye la piedra de toque de la calidad de una democracia”. La clave reside, por tanto, en igualar intervencionismo a autoritarismo; $\mathrm{y}$, al mismo tiempo, en oponer estos a libertad y democracia.

Los aspectos más criticados son el Consejo Estatal de la Información, “dependiente en última instancia de poder político", pues es nombrado por el Parlamento y financiado por los Presupuestos Generales del Estado. El secreto profesional, las competencias del director y los derechos de autor son otros asuntos que también se mencionan en sentido negativo, si bien con una intensidad más moderada.

Frente a la regulación específica de la información periodística, El País apuesta por la autorregulación y la aplicación de la legislación ordinaria, es decir, por lo que ya existe. Esta apuesta sorprende bastante, pues el rotativo no tiene reparos en afirmar que el periodismo español ha alcanzado "uno de los momentos más críticos de su historia reciente". En cualquier caso, queda claro que la postura del diario madrileño se inserta en la teoría libertaria, ya que prima la libertad de periodistas y empresas, en detrimento de un mayor control de las responsabilidades.

\subsubsection{El Mundo}

El periódico dirigido por Pedro J. RAmírez publica dos editoriales dedicados exclusivamente a comentar la Proposición de Ley de Estatuto del periodista profesional: uno, el 27 de noviembre de 2004; otro, el 6 de octubre de 2005. En ambos, El Mundo (1989) expone los motivos de su rechazo.

En el primero, el diario considera que "la iniciativa de IU peca de un aire ordenancista y corporativo que no responde a las necesidades de una sociedad democrática y choca con los principios de autonomía empresarial y libertad de mercado". Como puede observarse, la libertad y la democracia vuelven a situarse en primer lugar; ahora bien, en esta ocasión la libertad es fundamentalmente económica, con lo que queda claro que el rotativo se pone más fácilmente en el lugar del empresario que en el del profesional y, por supuesto, que en el del ciudadano. 
El Mundo también teme la burocratización del periodismo, así como el corporativismo, motivo por el cual sostiene que "si un profesional se equivoca o una empresa actúa al margen de la ley, deben ser los tribunales de justicia quienes exijan las correspondientes responsabilidades".

En el segundo editorial aumenta la intensidad, que pasa de media a fuerte, y se recurre al empleo de argumentos de tipo psicológico, al afirmar que la PLEPP supone "un retorno a la visión franquista de la profesión periodística".

La creación de una comisión deontológica que otorgue o retire credenciales, así como la obligación de crear comités de redacción, suscitan críticas parecidas a las del editorial anterior (control político, burocratización, intromisión en la libertad de empresa), si bien en esta ocasión el diario contempla la posibilidad de la autorregulación cuando considera que los comités de redacción "deberían funcionar de forma libremente pactada en cada medio".

Al igual que El País, la postura de El Mundo se encuadra dentro de la teoría libertaria de la prensa, si bien el rotativo de Pedro J. incide más en la autonomía empresarial y la libertad de mercado.

\subsubsection{ABC}

El diario $A B C$ (1903) difunde dos editoriales expresamente dedicados a la Proposición de Ley de Estatuto del periodista profesional, impresos el 5 y el 10 de octubre de 2005. Ambos se caracterizan por emplear una intensidad fuerte y utilizar un abundante número de elementos psicólogos; todo ello con el fin de atacar la PLEPP.

En el primer editorial, el diario considera que la proposición de ley constituye “una intromisión sin matices e inaceptable en la profesión”. Y los dos asuntos que se mencionan inmediatamente después son el carné y el Consejo Estatal de la Información. Este organismo, advierten los editorialistas, posee un "inquietante parecido en sus funciones con órganos del pasado" (elemento psicológico).

La alternativa al proyecto recae, una vez más, en la autorregulación, que “siempre es mejor solución que el trágala”, esto es, mejor solución que la regulación obligatoria.

El segundo artículo sigue la línea del anterior, aunque más radicalizada: “ $A B C$ se siente autorizado a criticar la esencia de un proyecto con ribetes estalinistas. Por supuesto, rechazamos el texto presentado, pero también cualquier alternativa de la misma naturaleza que se pudiera elaborar".

El rotativo madrileño, por citar ejemplos concretos, critica la inclusión de un código deontológico dentro del texto legal, pues ésta le recuerda a los tribunales de honor, prohibidos expresamente por la Constitución. Tampoco ve con buenos ojos la obligación de crear comités de redacción que sovieticen el ejercicio de la profesión periodística.

En el fondo, subyace una visión muy negativa del Estado y, por el contrario, una muy positiva de los medios de comunicación: "[Toda regulación legal] subvierte gravemente la filosofía democrática: son los medios de comunicación los que 
cumplen el papel de controladores del poder, nunca al revés”. La teoría libertaria sigue siendo la predominante.

\subsubsection{La Vanguardia}

El periódico catalán publica un único editorial, muy breve, el 31 de octubre de 2005. La Vanguardia (1881) considera que el periodismo español se halla aquejado de "profundos males" y, sin embargo, "el aparente remedio puede ser peor que la enfermedad”.

El argumento principal en el que se basa resulta bien conocido: "La mejor norma para controlar el ejercicio periodístico es la que no existe”. Se trata, una vez más, de evitar cualquier tipo de control sobre la información periodística. La alternativa recae, nuevamente, en la autorregulación, con lo que el cuarto y último periódico analizado vuelve a insertarse dentro de la teoría libertaria expuesta por SIEBERT, PETERSON y SCHRAMM.

\subsection{Otras voces del periodismo}

\subsubsection{Juan Varela}

El periodista y consultor de medios, Juan Varela (Betanzos, La Coruña, 1964), dedicó dieciséis artículos de su blog Periodistas 21 a la Proposición de Ley de Estatuto del periodista profesional entre el 17 de noviembre de 2004 y el 19 de septiembre de 2006.

El blogger es contrario a la aprobación de la PLEPP, tal y como se halla redactada. El principal argumento para rechazarla consiste en que "supone un grave peligro de politización", pues "somete la regulación del periodismo al poder político". El proyecto legal le parece además "demasiado reglamentista”, "anacrónico" y "corporativista”.

VARELA es claramente partidario de la autorregulación, compatible con la legislación ordinaria: "La autorregulación al estilo británico de la Press Complaint Commission y el sometimiento a las leyes y los tribunales son las únicas autoridades que reconocemos algunos creyentes en el periodismo independiente”.

No obstante, el consultor admite en otro lugar que "una mejor regulación de algunos aspectos de la profesión puede beneficiar a todos", si bien -se sobreentiende- no a través de una regulación específica. El periodista digital insiste, por ejemplo, en la importancia de que los derechos de acceso se amplíen no sólo a los periodistas, sino también al resto de ciudadanos.

Por el contrario, el blogger se muestra contrario a regular otros aspectos de la proposición como la titularidad, la acreditación, los comités de redacción, los consejos de información y el código deontológico. De entre todos, la acreditación y los consejos de la información son los que le producen mayor aversión.

El periodista es, por tanto, partícipe de la teoría libertaria, así como de la democrático-participativa, pues insiste continuamente en la importancia de conceder a la ciudadanía unos derechos que le permitan el ejercicio del periodismo. 


\section{Conclusiones}

Nadie ha puesto en duda la importancia de la información periodística para la conformación de una sociedad democrática. Tampoco se ha cuestionado la necesidad de profesionales capaces de seleccionar lo más importante para la comunidad, comprenderlo rápidamente y comunicarlo de forma rigurosa y atractiva. Con más apertura al ciudadano, con más diálogo, pero con calidad y responsabilidad o, lo que es lo mismo, con profesionalidad.

Y, sin embargo, el acuerdo parece hallarse a luz de distancia. La admisión a trámite de la Proposición de Ley de Estatuto del periodista profesional ha puesto de manifiesto que existen profundas divergencias a la hora de decidir cuál es la mejor forma de garantizar el derecho a la información de los ciudadanos y, para ello, cómo defender a los profesionales que quieren permanecer fieles al sentido de su trabajo. Veamos algunas de las respuestas, en forma de conclusiones.

\section{a) La PLEPP, un medio que no justifica el fin}

La proposición de ley ha sido ampliamente rechazada, a pesar de que algunos han reconocido el esfuerzo de los promotores por mejorar la información periodística (Jáuregui, Reviriego, Aguilar, Fontán, El País, La Vanguardia, Varela). Los aspectos más criticados, por este orden, han sido: consejos de la información, carné acreditativo de la condición de profesional y comités de redacción.

Los consejos de la información han sido rechazados sobre todo por dejar en manos del poder político el nombramiento de sus integrantes. El riesgo es real, y ahí está la constante apelación a la experiencia franquista. Sin embargo, tampoco puede obviarse el hecho de que en democracia son los poderes públicos quienes tienen la legitimidad y el deber de garantizar los derechos de los ciudadanos, entre los que se encuentra el derecho a la información.

La concesión de un carné por parte del Consejo Estatal de la Información también ha levantado suspicacias. Tanto por la mala experiencia sufrida durante la dictadura de Franco como por la desconfianza existente entre los mismos profesionales, que temen sirva para utilizarlo en beneficio propio (GozALo, Aguilar, El Mundo, VArela) o atacarse entre sí (Márquez ReVIRIEGo).

Finalmente, los comités de redacción, caso paradigmático de las dificultades que existen para encontrar un equilibrio entre el derecho del empresario a manejar su inversión económica como le mejor le plazca y los derechos de los trabajadores a participar en el devenir del medio, para buscar una fórmula democrática sin caer en la tiranía ni en la anarquía, lo tan mentados sóviets.

\section{b) Ética profesional y legislación ordinaria, un binomio insuficiente}

La mayoría de los profesionales y medios analizados ha optado por reforzar lo que ya existe, decantándose por una fórmula que combina la ética profesional con la legislación ordinaria (JÁuregui, Gozalo, Márquez Reviriego, Fontán, El País, El Mundo, ABC, La Vanguardia, Varela). Ahora bien, la ética profesional a veces se entiende como autorregulación colectiva (JÁUREguI, Fontán, Aguilar, los medios y VARELA) y otras veces como ética personal del individuo (Gozalo, Reviriego). 
En el caso de la autorregulación, los comparecientes y El País son conscientes de que ésta presenta insuficiencias. Sin embargo, Fernando JÁUREGUI y Miguel Ángel AguiLAR parecen ser los únicos que verdaderamente creen en la eficacia de esta opción, pues sugieren propuestas concretas (buzones de denuncia y organismo de autorregulación; o comisiones de prensa, respectivamente). Lamentablemente, estas opciones no parecen realistas, por dos motivos: porque ya existían en el momento de sus intervenciones y porque las organizaciones periodísticas han demostrado su incapacidad para unirse y crear un organismo deontológico de ámbito nacional.

La otra opción, la ética profesional, nos parece incluso menos realista, pues deja en manos de cada persona la responsabilidad de luchar contra instituciones y dinámicas globales que no pueden cambiarse con la sola fuerza del individuo.

La defensa de la legislación ordinaria, por otra parte, tampoco implica negar sus limitaciones, tal y como reconocen claramente Jáuregui o Aguilar. Otros no merecen ser tenidos en cuenta, pues caen en profundas contradicciones que les llevan a defender la legislación ordinaria, aun sabiendo que no recurrieron a ella cuando debían (GozALO); o a respaldar la regulación ordinaria salvo en lo que les interesa, como la legislación laboral (MárQUez Reviriego). Además, ninguno de los discursos seleccionados explica cómo se podría reforzar el cumplimiento de la legislación ordinaria vigente.

\section{c) La regulación específica como un mal necesario}

Dardo Gómez y, en menor medida, Miguel Ángel Aguilar y Antonio FonTán, son los únicos que defienden una regulación específica de la profesión periodística. Esta aceptación no implica un rechazo de la deontología, más bien todo lo contrario: porque la autorregulación es ineficaz, es preciso recurrir al derecho.

Otra cuestión diferente es dónde deben situarse los límites entre ambas disciplinas normativas. Así, mientras algunos critican que se haya incluido un código deontológico en una norma jurídica (Aguilar, Fontán, El País, La Vanguardia, VArela), los promotores del texto, como Gómez, defienden su presencia en la proposición.

\section{d) El derecho a la información no está garantizado}

La mayoría de los periodistas y medios de comunicación dan por hecho que el periodismo español atraviesa una situación complicada, con problemas diversos y variados: específicos de los periodistas (intrusismo, escasas garantías para hacer efectiva la cláusula de conciencia y el secreto profesional, formación deficiente), relativos a la relación entre periodistas y empresarios (precariedad laboral, falta de mecanismos para fomentar la participación en los medios) y propios de los profesionales con los ciudadanos (manipulación, confusión, indefensión).

Como puede observarse, están presentes algunos de los problemas mencionados en el capítulo segundo, lo cual corrobora la importancia de este trabajo, que indaga sobre la mejor forma de garantizar un periodismo responsable. 


\section{e) El reto, conciliar visiones y actitudes antagónicas}

A lo largo de este trabajo han salido a relucir visiones y actitudes antagónicas que merecen ser tenidas en cuenta de cara a una posible conciliación de las mismas, deseable en la medida en que nadie puede ser excluido de la comunidad por sus opiniones o creencias.

Por lo que se refiere a las visiones del mundo, creemos que la más importante se refiere a la relación entre la libertad de las personas (físicas o jurídicas) y el Estado, Gobierno o la clase política. Para los que rechazan la PLEPP, la libertad de periodistas y empresarios está por encima de cualquier regulación (teoría libertaria o libertad negativa). Por el contrario, para Dardo Gómez y los profesionales más sensibles a las consecuencias de sus actos, la libertad de algunos puede ser legítimamente limitada si se demuestra que daña la libertad de terceras personas (teoría de la responsabilidad o libertad positiva).

En los dos casos, subyace una visión un tanto maniquea y, por tanto, distorsionada del problema. Así, en el primero subsiste una visión negativa de la clase política y una visión positiva de los informadores y las empresas periodísticas, mientras que en el segundo ocurre -casi- todo lo contrario: una visión positiva de los poderes públicos y una visión negativa, no de los periodistas, sino de los empresarios.

Para unos, el problema principal sigue siendo el poder político, tal y como sucedía cuando se aprobó la Constitución norteamericana y su primera enmienda, allá por el siglo XVIII. Para otros, el problema se ha desplazado: el enemigo actual no es tanto la clase política como el poder económico.

La percepción del asunto varía en función del puesto ejercido por los emisores. Así, los periodistas que han ejercido durante más años como directivos (GozALO, FonTÁn, AgUILAR) y los editorialistas de todos los medios de comunicación son los que más se oponen a la participación de los periodistas dentro de la empresa, a través de los comités de redacción.

Las diferentes posturas también se aprecian a la hora de entender el papel de medios y periodistas. Los defensores de la teoría liberal ofrecen una visión idealizada de los medios, que califican de contrapoder (El Mundo, ABC, Varela). Los más conscientes de la responsabilidad de medios y/o profesionales, sin embargo, poseen una visión más humilde (Jaúregui) e incluso más a ras de suelo (MÁrquez ReVIRIEgo, Gómez).

Merece la pena destacar que, tanto unos como otros, defienden el derecho universal a la información, pero para defender posiciones contrarias. Así, los detractores de la regulación específica suelen argumentar que legislar la profesión periodística constituye un agravio comparativo respecto a los derechos de cualquier ciudadano (Gozalo, Márquez Reviriego, Fontán, El Mundo, Varela). Los defensores de la regulación específica, por el contrario, consideran que sólo regulando el periodismo es posible garantizar el pleno ejercicio de ese derecho universal.

En el fondo, subyace una visión diferente de los derechos de los ciudadanos. Para los primeros, los ciudadanos han de limitarse a comprar, ver o escuchar el medio que les interesa, y poco más (Gozalo, El País). Para los segundos, los ciudadanos se merecen mayores garantías (JÁUREgUI, AguILAR, GóMEz, VARELA). 
Como puede observarse, periodistas y medios de comunicación se unen para defender su libertad de expresión e información frente al Estado, pero se separan cuando llega el momento de repartir responsabilidades: directivos y editorialistas, para defender su libertad a toda costa; los periodistas, para reclamar su propia protección y la de los ciudadanos. La lógica ideológica domina, por tanto, en todos los actores, pero se bifurca en económica para los profesionales más próximos a los propietarios de los medios.

En cuanto a las visiones del mundo, este trabajo espera haber mostrado que en el debate sobre la PLEPP han faltado actitudes serenas, constructivas y esperanzadas.

La mayoría de profesionales y medios analizados ha apelado, de una u otra forma, al miedo. A todos, menos a Dardo Gómez y La Vanguardia, la proposición objeto de estudio les ha traído a la memoria el régimen dictatorial de Francisco Franco. No obstante, es posible establecer grados, desde la levedad de las menciones de Jáuregui y Aguilar, hasta la intensidad de GozALO, MÁRQUEz REviRIEGO, FontáN o El Mundo. El discurso más radical, sin duda, es el elaborado por los editorialistas de $A B C$.

La comparación de la PLEPP con el régimen franquista nos parece falaz, en la medida en que presupone que un mismo instrumento (un organismo que acredite la profesionalidad y vele por ella) funcionará igual en un régimen dictatorial que en uno democrático. Quienes sostienen que nos hallamos ante una mera vuelta al pasado -como si eso fuera posible-, introducen el miedo en sus receptores y bloquean cualquier diálogo racional sobre la cuestión. Sólo de este modo se explica la paradójica conclusión de quienes reconocen la problemática existente y, al mismo tiempo, optan por dejar las cosas como están.

A lo largo de esta investigación también se ha percibido una actitud de sospecha, desconfianza o escepticismo. Nos referimos a aquellos que han dudado acerca de la viabilidad de la proposición de ley, por motivos como la politización o el partidismo (Jáuregui, Fontán, Márquez Reviriego, El País, El Mundo, ABC, La Vanguardia, Varela), el corporativismo (Jáuregui, Gozalo, Márquez Reviriego, El País, El Mundo, Varela) o, simplemente, el interés propio (Aguilar, Gozalo, Márquez Reviriego, El Mundo, VArela).

Ojo. No se reprocha que los citados se hayan percatado de estos peligros, totalmente reales. La objeción reside, más bien, en la falacia de la generalización, esto es, en creer que, porque haya personas que no puedan o no quieran mantenerse fieles a su tarea, no pueda haberlas nunca. Es decir, el problema radica en que, en el fondo, subyace una desconfianza en la condición humana difícil de rebatir con argumentos lógicos.

En algunas ocasiones, también se percibe una cierta desconfianza en la capacidad de los seres humanos para distinguir lo que está bien y lo que está mal. MÁrQUEZ REVIRIEGo y $A B C$ se han mostrado especialmente preocupados por la cuestión de la veracidad, cuando el Tribunal Constitucional ya posee jurisprudencia asentada sobre la cuestión. 
Finalmente, se percibe una cierta resignación o conformismo entre quienes se han posicionado en contra de la PLEPP. Por la escasez de propuestas realistas y concretas. Por la abundancia de argumentos psicológicos. Todo ello a pesar de que la mayoría, periodistas directivos o no, coinciden en que el derecho de los ciudadanos no está garantizado.

Si esto continúa siendo cierto a día de hoy, tal y como parece probable, ¿quién o quiénes son los responsables que, en última instancia, deben velar por los derechos de los españoles? La Constitución Española lo deja muy claro en su artículo 9.2: "Corresponde a los poderes públicos promover las condiciones para que la libertad y la igualdad del individuo y de los grupos en que se integra sean reales y efectivas; remover los obstáculos que impidan o dificulten su plenitud y facilitar la participación de todos los ciudadanos en la vida política, económica, cultural y social”.

\section{Referencias bibliográficas}

ASOCIACIÓN DE LA PRENSA DE MADRID (2004-2008): Anuario de la profesión periodística. Madrid, Asociación de la Prensa de Madrid.

ASOCIACIÓN DE TELESPECTADORES Y RADIOYENTES y CENTRO UNIVERSITARIO VILLANUEVA (2006): III Informe ATR-Villanueva. Seguimiento del código de autorregulación (firmado el 9 de diciembre de 2004). Madrid, 15 junio 2006: http://www.ucm.es/info/vivataca/ficheros/n77/ IIIINFORMEATRVILLANUEVAjunio2006.pdf [fecha de consulta: 3 de noviembre de 2010]

AZNAR, Hugo (2005): Comunicación responsable. La autorregulación de los medios. Barcelona, Ariel.

BARDIN, Laurence (1986): Análisis de contenido. Madrid, Akal.

CABALLERO LÓPEZ, José Antonio (2000): “Retórica de la oratoria parlamentaria de Práxedes Mateo Sagasta. El discurso sobre la libertad de cultos”, en OLLERO VALLÉS, José Luis (coord.): Berceo, $\mathrm{n}^{\circ}$ 139. Logroño, Instituto de Estudios Riojanos, pp. 145-165: http://dialnet.unirioja.es/servlet/ articulo?codigo=61946 [fecha de consulta: 3 de noviembre de 2010]

CARRERAS SERRA, Lluís de (2008): Las normas jurídicas de los periodistas. Derecho español de la información. Barcelona, UOC.

DEMERS, Francois (1998): “Teorías normativas’ de la prensa y ‘tipos ideales’ para interpretar los discursos sobre el periodismo”, en Comunicación y Sociedad, $\mathrm{n}^{\circ}$ 34. México, Universidad de Guadalajara, pp. 59-84: http://www.allbusiness.com/ sector-61-educational-services/741360-1.html [fecha de consulta: 3 de noviembre de 2010]

ESTEFANÍA, Joaquín (2008): Informe sobre la Democracia en España 2008. Madrid, Fundación Alternativas.

GÓMEZ, Dardo (2010): Conferencia sobre el estatuto del periodista profesional organizada por el Sindicato de Periodistas de Cataluña. Tarragona, 22 enero 2010.

HERRERA, Joan (2010): Conferencia sobre el estatuto del periodista profesional organizada por el Sindicato de Periodistas de Cataluña. Tarragona, 22 enero 2010. 
JIMÉNEZ GÓMEZ, Eva (2010): Autorregulación versus regulación. El discurso periodístico sobre la Proposición de Ley de Estatuto del periodista profesional. Barcelona, Facultad de Comunicación Blanquerna. Trabajo inédito.

KOVACH, Hill y ROSENSTIEL, Tom (2003): Los elementos del periodismo. Madrid, El País.

LÓPEZ HIDALGO, Antonio (2006): "Precariedad laboral, nuevas rutinas de trabajo y ejercicio libre del periodismo", en IX Congreso Ibercom. Sevilla-Cádiz: http://alojamientos.us.es/cibercom/pdf/LopezHidalgoAntonio.pdf [fecha de consulta: 3 de noviembre de 2010]

MANJÓN, Pilar (2004): Comparecencia ante la Comisión del 11-M, en El Mundo.es. 15 de diciembre:

http://estaticos.elmundo.es/documentos/2004/12/15/asociacionafectados11m.pdf [fecha de consulta: 3 de noviembre de 2010]

MCQUAIL, Denis (2000): Introducción a la teoría de la comunicación de masas. Barcelona-Buenos Aires-México, Paidós.

NAVARRO MARCHANTE, Vicente y RODRÍGUEZ BORGES, Rodrigo Fidel (2004): "Pero, ¿está en vigor la cláusula de conciencia de los periodistas? Balance de siete años de regulación”. 16 de noviembre: http://upf.edu/periodis/ Congres_ahc/Documents/Sesio1/NavarroFidel.htm [fecha de consulta: 16 de febrero de 2010]

RAMOS FERNÁNDEZ, Luis Fernando (2003): “Aplicación y eficacia del código deontológico de la FAPE. La indiferencia de los medios ante una pauta ética general para los periodistas españoles”, en Veracidad y objetividad: desafíos éticos en la sociedad de la información. Valencia, Fundación Coso.

RODRÍGUEZ ZAPATERO, José Luis (2003): Intervención del Secretario General del PSOE, José Luis Rodríguez Zapatero, en Clausura de la jornada parlamentaria 'Derechos a la información, derechos de los informadores'. 25 noviembre: http://www.fesp.org/docs/Derechos_a_la_informacion.pdf [fecha de consulta: 3 de noviembre de 2010]

RUIZ, Carlos (2008): La agonía del cuarto poder. Prensa contra democracia. Barcelona, Trípodos.

SÁNCHEZ ARANDA, José Javier (2005): “Análisis cuantitativo de medios”, en BERGANZA CONDE, Rosa y RUIZ SAN ROMÁN, José A. (coords.): Investigar en Comunicación. Guía práctica de métodos y técnicas de investigación social en Comunicación. Madrid, McGrawHill-Interamericana de España, pp. 207-228.

ROVIRA, Jordi (2007): “Història d'una conspiració. Dossier especial 11-M”, en COL·LEGI DE PERIODISTES DE CATALUNYA. Capçalera, número especial.

SIEBERT, Fred S. et al. (1963): Four theories of the press. The autoritharian, libertarian, social responsibility and soviet comunist concepts of what the press should be and do. Urbana-Chicago, University of Illinois Press.

VAN DIJK, Teun A. (2000): "El discurso como interacción en la sociedad”, en VAN DIJK, Teun A. (comp.): El discurso como interacción social. Barcelona, Gedisa. 
WOLTON, Dominique (1999): Sobre la comunicación. Una reflexión sobre sus luces y sus sombras. Madrid, Acento.

ZARZALEJOS, José A. (2008): "No he tenido nunca presiones tan fuertes como las de Esperanza Aguirre”, en ROVIRA, Jordi: Capçalera, julio-septiembre. http://www.cadenaser.com/csermedia/cadenaser/media/200810/27/espana/20081 027csrcsrnac_1_Pes_PDF.pdf [fecha de consulta: 3 de noviembre de 2010]

\section{Anexos}

\begin{tabular}{|c|c|c|}
\hline Fecha & Mecanismo & Medio/Organización \\
\hline $\begin{array}{l}\text { Diciembre } \\
1990\end{array}$ & Estatuto de redacción & E1 Mundo \\
\hline Julio 1991 & Estatuto (marco) de redacción & $\begin{array}{l}\text { Colegio de Periodistas de } \\
\text { Cataluña }\end{array}$ \\
\hline 1991 & Libro de estilo & Canal Sur Televisión \\
\hline 1.11 .1992 & Código deontológico & $\begin{array}{l}\text { Colegio de Periodistas de } \\
\text { Cataluña }\end{array}$ \\
\hline 1992 & Libro de estilo & Televisión de Galicia \\
\hline 26.3 .1993 & $\begin{array}{l}\text { Convenio para la protección de la } \\
\text { infancia y juventud }\end{array}$ & $\begin{array}{l}\text { Ministerio de Educación y } \\
\text { Ciencia, Consejerias de } \\
\text { Educación y cadenas de } \\
\text { televisión públicas y privadas }\end{array}$ \\
\hline Mayo 1993 & Libro de estilo & $\mathrm{ABC}$ \\
\hline 26.7.1993 & Libro de estilo & Telemadrid \\
\hline $\begin{array}{l}\text { Noviembre } \\
1993\end{array}$ & Estatuto de redacción & El Periódico de Cataluña \\
\hline 28.11 .1993 & Código deontológico & $\begin{array}{l}\text { Federación de Asociaciones } \\
\text { de la Prensa de España (FAPE) }\end{array}$ \\
\hline $\begin{array}{l}\text { Noviembre } \\
1993\end{array}$ & Defensor del lector & La Vanguardia \\
\hline 25.4.1994 & Código deontológico & Grupo Correo \\
\hline 4.1 .1995 & Código deontológico & Canal Sur Televisión \\
\hline 1.2 .1995 & Defensor del lector & E1 Punt (Gerona) \\
\hline 1995 & Libro de estilo & Mundo Deportivo \\
\hline 1995 & Defensor del espectador & Canal Sur TV \\
\hline $\begin{array}{l}\text { Septiembre } \\
1996\end{array}$ & Defensor del oyente & Canal Sur Radio \\
\hline 19.9 .1996 & Estatuto de redacción & Radiotelevisión valenciana \\
\hline 1996 & Defensor & Regió 7 (Mranresa) \\
\hline 1996 & Libro de estilo & El Mundo \\
\hline 1996 & Libro de estilo & Onda Cero Radio \\
\hline 1996 & Estatuto de redacción & $\begin{array}{l}\text { Corporació Catalana de } \\
\text { Mitjans Audiovisuals }\end{array}$ \\
\hline 1996 & Consejo audiovisual & Consejo Audiovisual de \\
\hline
\end{tabular}

' El listado tiene un carácter orientativo, no exhaustivo. 


\begin{tabular}{|c|c|c|}
\hline & & Cataluña \\
\hline 1.1 .1997 & $\begin{array}{l}\text { Consejo de la Información de } \\
\text { Cataluña }\end{array}$ & $\begin{array}{l}\text { Colegio de Periodistas de } \\
\text { Cataluña }\end{array}$ \\
\hline 18.8 .1997 & Código deontológico & Antena 3 Televisión \\
\hline 1.12 .1997 & Defensor & Antena 3 Televisión \\
\hline 24.12 .1998 & $\begin{array}{l}\text { Estatuto de redacción } \\
\text { Estatuto (marco) de redacción }\end{array}$ & $\begin{array}{l}\text { Corporación catalana de radio } \\
\text { y televisión } \\
\text { El Punt }\end{array}$ \\
\hline 18.2 .1999 & Libro de estilo & Antena 3 Televisión \\
\hline 1999 & Código deontológico & CNN Plus \\
\hline 1999 & Código deontológico & $\begin{array}{l}\text { Agrupación General de } \\
\text { Periodistas de UGT }\end{array}$ \\
\hline Marzo 2000 & Código deontológico & $\begin{array}{l}\text { Sindicato de Periodistas de } \\
\text { Madrid }\end{array}$ \\
\hline 2000 & Estatuto de redacción & Radiotelevisión valenciana \\
\hline Abril 2001 & Defensor & La Voz de Galicia \\
\hline 26.06 .2001 & Estatuto de redacción & La Vanguardia \\
\hline 2001 & Consejo audiovisual & $\begin{array}{lll}\text { Consejo } & \text { Audiovisual de } \\
\text { Navarra } & & \\
\end{array}$ \\
\hline Abril 2002 & Estatuto de redacción & Sport \\
\hline Julio 2002 & Libro de estilo & La voz de Galicia \\
\hline 2002 & Principios de actuación & $\begin{array}{l}\text { Corporación catalana de radio } \\
\text { y televisión }\end{array}$ \\
\hline 2002 & Libro de estilo & La voz de Asturias \\
\hline 2002 & Libro de estilo & Mediterráneo \\
\hline 2002 & Libro de estilo & La Opinión de Tenerife \\
\hline 2002 & $\begin{array}{l}\text { Estatuto de redacción/ } \\
\text { Código deontológico }\end{array}$ & El Punt \\
\hline Marzo 2003 & Libro de estilo & El Periódico de Cataluña \\
\hline 2003 & Libro de estilo & Cadena COPE \\
\hline 2003 & Libro de estilo & Grupo Vocento \\
\hline Febrero 2004 & $\begin{array}{l}\text { Protocolo sobre principios de } \\
\text { autorregulación }\end{array}$ & $\begin{array}{llll}\text { Consejo } & \text { Audiovisual } & \text { de } \\
\text { Navarra y } & \text { y cadenas } & \text { de } \\
\text { televisión } & & & \end{array}$ \\
\hline Marzo 2004 & Libro de estilo & $\begin{array}{l}\text { Canal Sur Televisión y Canal } \\
2 \text { Andalucia }\end{array}$ \\
\hline Mayo 2004 & Consejo deontológico & FAPE \\
\hline
\end{tabular}




\begin{tabular}{|c|c|c|}
\hline $\begin{array}{l}\text { Diciembre } \\
2004\end{array}$ & $\begin{array}{l}\text { Acuerdo y código para la defensa } \\
\text { de la infancia en los contenidos } \\
\text { televisivos }\end{array}$ & $\begin{array}{l}\text { Gobierno y representantes de } \\
\text { las televisiones españolas }\end{array}$ \\
\hline 2004 & Defensor & E1 Correo Gallego \\
\hline 2004 & Libro de redacción & La Vanguardia \\
\hline 2004 & Consejo audiovisual & $\begin{array}{lll}\text { Consejo Audiovisual de } \\
\text { Andalucía }\end{array}$ \\
\hline 19.1 .2005 & Estatuto de redacción & Radiotelevisión andaluza \\
\hline $\begin{array}{l}\text { Noviembre } \\
2005\end{array}$ & Libro de estilo & Grupo Rayet \\
\hline 2.2 .2006 & Defensor & Radiotelevisión española \\
\hline 22.3 .2006 & Estatuto de redacción & Agencia EFE \\
\hline $\begin{array}{l}2006 \\
2006 \\
2007\end{array}$ & $\begin{array}{l}\text { Libro de estilo } \\
\text { Libro de estilo } \\
\text { Libro de estilo }\end{array}$ & $\begin{array}{l}\text { Agencia Servimedia } \\
\text { Berria } \\
\text { Barcelona TV }\end{array}$ \\
\hline Abril 2008 & Estatuto de información & Corporación RTVE \\
\hline $\begin{array}{l}\text { Diciembre } \\
2008\end{array}$ & Código deontológico & $\begin{array}{l}\text { Colegio Profesional de } \\
\text { Periodistas de Galicia }\end{array}$ \\
\hline $\begin{array}{l}\text { Diciembre } \\
2008\end{array}$ & Libro de estilo & ComRàdio \\
\hline
\end{tabular}

